\title{
Accidental overdose in the deep shade of night: a warning on the assumed safety of 'natural substances'
}

\author{
Andrew Chadwick, Abigail Ash, James Day, Mark Borthwick
}

Adult Intensive Care Department, Oxford University Hospitals NHS Trust, Oxford, UK

\section{Correspondence to} Dr Andrew Chadwick, achadwick@doctors.net.uk

Accepted 2 October 2015

\section{CrossMark}

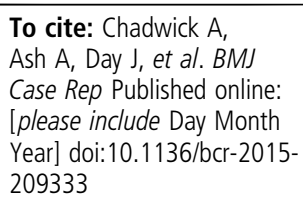

\section{SUMMARY}

There is an increasing use of herbal remedies and medicines, with a commonly held belief that natural substances are safe. We present the case of a 50-yearold woman who was a trained herbalist and had purchased an 'Atropa belladonna (deadly nightshade) preparation'. Attempting to combat her insomnia, late one evening she deliberately ingested a small portion of this, approximately $50 \mathrm{~mL}$. Unintentionally, this was equivalent to a very large $(15 \mathrm{mg})$ dose of atropine and she presented in an acute anticholinergic syndrome (confused, tachycardic and hypertensive) to our accident and emergency department. She received supportive management in our intensive treatment unit including mechanical ventilation. Fortunately, there were no longterm sequelae from this episode. However, this dramatic clinical presentation does highlight the potential dangers posed by herbal remedies. Furthermore, this case provides clinicians with an important insight into potentially dangerous products available legally within the UK. To help clinicians' understanding of this our discussion explains the manufacture and 'dosing' of the A. belladonna preparation.

\section{BACKGROUND}

'Atropa belladonna', or 'deadly nightshade', is often associated with literary references describing the use of the plant by women to induce mydriasis to make themselves appear more seductive. Atropine is commonly used in Western medicine, for example, in the treatment of bradycardia. In herbal medicine, the anticholinergic effects of $A$. belladonna are used to alleviate 'nervous' pain, muscle spasm and to reduce secretions. Most cases of belladonna poisoning occur from direct ingestion of the plant's berries. ${ }^{1}$ However, our case report describes the first published account of accidental atropine poisoning where atropine was obtained for professional herbalist purposes. It therefore highlights important safety considerations. The product involved was purchased legally for the intended beneficial effects, yet a small volume, just $50 \mathrm{~mL}$, was able to produce almost fatal effects.

\section{CASE PRESENTATION}

A 50-year-old woman presented confused (Glasgow Coma Scale 7/15), flushed and tachycardic (heart rate $163 \mathrm{bpm}$ ) to our emergency department.

Her husband explained that she had longstanding insomnia and, as normal for her, despite $7.5 \mathrm{mg}$ of zopiclone, she had remained unsettled and withdrew downstairs. After hearing a commotion, the husband went downstairs to find his wife in a 'giggling' and intoxicated state (she had a longstanding abstinence from alcohol). He therefore helped her to bed. However, he was woken a second time when she had left the bed and fallen; this time she was more overtly confused, so an ambulance was called.

In the resuscitation room, the patient was tachycardic, hypertensive (180/110) and confused. Furthermore, she was flushed and sweaty though normothermic, and had bilateral dilated and slowly responding pupils. Given the severity of her agitation and diagnostic uncertainty, a modified rapid sequence intubation was undertaken. Intubation and sedation facilitated a safe transfer to the CT scanner, which revealed a normal CT of the brain. Then she was admitted to the intensive care unit for overnight care.

Over the following $6 \mathrm{~h}$, her tachycardia improved from 130 to 105 and on sedation hold in the morning she was entirely appropriate, allowing for successful extubation. This allowed for a collateral history regarding the events of the previous night. She was a trained herbalist and had purchased 'Atropa belladonna preparation'. During the night, to combat her insomnia, she had taken a drink directly from the bottle. This produced the dramatic anticholinergic poisoning syndrome described above.

\section{DIFFERENTIAL DIAGNOSIS}

Atropine acts as a competitive antagonist for the muscarinic acetylcholine receptors. Therefore, at its poisoning dose, it produces an almost complete block of the parasympathetic nervous system. This allows the symptoms to be predicted with the classic descriptive terms presented in table $1 .^{2} 3$

Most cases of atropine poisoning, intentional or otherwise, occur due to the ingestion of berries or plant material. Children are often poisoned by inadvertently ingesting A. belladonna berries. The subsequent anticholinergic toxidrome can have varying degrees of severity. ${ }^{4}$ Adult atropine poisoning is less commonly reported. Cases of mistaking A. belladonna for blueberries, or deliberate ingestion to cause self-harm, have been reported. ${ }^{4-6}$ Atropine poisoning has also been associated with rhabdomyolysis, pancreatitis and a subdural haematoma.?

However, given the wide variety of symptoms mentioned above, any condition that can cause a 
Table 1 Symptoms of anticholinergic syndrome

\begin{tabular}{|c|c|}
\hline Description & Mechanism \\
\hline Red as a beet & $\begin{array}{l}\text { Compensating for the loss of sweat leads to excessive } \\
\text { vasodilation of the skin to maximise heat loss }\end{array}$ \\
\hline Dry as a bone & $\begin{array}{l}\text { Muscarinic action causes sweat glands to activate, } \\
\text { therefore, anticholinergics cause anhidrosis (absence of } \\
\text { sweat) }\end{array}$ \\
\hline Hot as a hare & $\begin{array}{l}\text { The removal of the normal thermal haemostasis } \\
\text { mechanisms often results in high fever }\end{array}$ \\
\hline Blind as a bat & $\begin{array}{l}\text { Pupillary constriction and accommodation rely on } \\
\text { muscarinic receptors, therefore, anticholinergics cause } \\
\text { pupillary dilation and blurry vision }\end{array}$ \\
\hline Mad as a hatter & $\begin{array}{l}\text { The loss of central nervous system muscarinic receptor } \\
\text { action can lead to a range of symptoms from anxiety, } \\
\text { delirium, visual hallucinations through to seizures and } \\
\text { coma }\end{array}$ \\
\hline Full as a drum & $\begin{array}{l}\text { Both the detrusor muscle and urinary sphincter are } \\
\text { under muscarinic control and therefore anticholinergics } \\
\text { will lead to a decreased signal to urinate and an } \\
\text { increase in urinary retention }\end{array}$ \\
\hline Non-mnemonic & $\begin{array}{l}\text { Loss of muscarinic receptors means there is unopposed } \\
\text { sympathetic action on the heart, giving tachycardia. } \\
\text { There is also slowing (or complete absence) of bowel } \\
\text { sounds }\end{array}$ \\
\hline
\end{tabular}

combination of tachycardia, altered mental status, urinary retention and possibly seizures can be included in the differential diagnosis of atropine poisoning. ${ }^{8}$

We will consider, first, other poisons that can mimic this and, second, non-poisoning differential diagnoses.

Some poisons will cause a true anticholinergic response. In our case, the plant was deadly nightshade, however, there are also woody and common nightshade plants. ${ }^{4}$ Furthermore Jimson weed ${ }^{9}$ (a plant occasionally smoked recreationally) contains anticholinergic alkaloids at high enough concentration to poison. Finally medicinal atropine (or other anticholinergic drugs) can be taken in overdose through accident or intention-

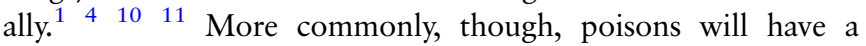
degree of anticholinergic response but also other effects. The most significant class of drugs of this type are the tricyclic antidepressants. Although they will cause an anticholinergic syndrome, their effects on cardiac sodium channels cause the classic QRS prolongation and their $\alpha$-blockade can result in significant hypotension. ${ }^{12}$ These clinical aspects tend to predominate in their poisoning. Phenothiazine derived drugs also cause anticholinergic affects. ${ }^{13}$ This chemical class makes up a variety of antihistamine (eg, prochlorperazine) and antipsychotic (eg, chlorpromazine) medications. Although theoretically use of these substances could present as an anticholinergic syndrome, their hypotensive and sedating actions tend to predominate. Many of the symptoms from anticholinergic poisoning result from unopposed sympathetic system activity, therefore, poisoning by sympathomimetics can result in a very similar clinical paradigm. Hence, overdose of methamphetamine, ${ }^{14}$ cocaine, ${ }^{15}$ or even cough mixtures (due to the phenylephrine) are an important differential; however, a key difference is that these all tend to produce excessive sweating and the mydriasis is less marked. Furthermore, methamphetamines often present with more prominent psychosis and cocaine is marked by extreme hypertension and restlessness. A final key overdose differential in a patient who is hyperthermic, agitated and tachycardic, is salicylate poisoning. This in part is because of the ease of its supply. Aspirin poisoning tends to produce tinnitus, nausea and the classical blood gas changes of progression from respiratory alkalosis to metabolic acidosis, all of which can differentiate it from the anticholinergic poisonings. ${ }^{16}$

Important non-overdose differentials to consider include sepsis (particularly from a neurological source), serotonin syndrome and neuroleptic malignant syndrome. Central nervous system (CNS) infection can cause all the symptoms listed above but the temporal progression of the symptoms can often help differentiate this; the delirium associated with anticholinergic poisonings tends to have a sharp onset time as opposed to a more gradual action of inflammatory processes. Serotonin syndrome occurs in response to excessive CNS serotonin levels. ${ }^{17}$ This can be seen in overdose of the selective serotonin reuptake inhibitors (SSRIs), but their very large therapeutic window makes this a rare presentation. Therefore, it is more commonly seen as a side effect when SSRIs are taken over a longer period of time and augmented either by a dose increase or further medications (eg, ondansetron). It can also be seen in Carcinoid syndrome from serotonin-secreting tumours. Serotonin syndrome will result in a flushed, agitated and hyperpyrexic patient. However, it also causes sweating and neuromuscular hyper-reactivity (tremor, hyper-reflexia, myoclonus), which differentiate it from anticholinergic poisoning. Finally, neuroleptic malignant syndrome is a key differential. ${ }^{18} 19$ This rare syndrome can occur with any of the antipsychotic medications or on withdrawal of Parkinson's treatments. The pathogenesis is thought to revolve around dopamine inactivity in the hypothalamus (either via receptor blockade or loss of substrate, respectively). This causes a hyperpyrexia, autonomic dysregulation (mimicking any of the symptoms above) and Parkinson's symptoms. These latter symptoms again act as a differentiator from both anticholinergic poisoning and also serotonin syndrome. ${ }^{18} 19$

\section{TREATMENT}

As mentioned in our case presentation, she was suffering from very severe agitation. Therefore, to ensure her safety, and to facilitate safe investigation of her state, we proceeded to immediate intubation. We performed this using $100 \mu \mathrm{g}$ fentanyl, $170 \mathrm{mg}$ propofol and $60 \mathrm{mg}$ rocuronium, sedation was then maintained with propofol and fentanyl infusions $(12 \mathrm{mg} / \mathrm{h}$ and $50 \mu \mathrm{g} / \mathrm{h}$, respectively). During her $10 \mathrm{~h}$ of treatment, $4.5 \mathrm{~L}$ of crystalloid rehydration occurred.

However, in most cases of atropine poising, the cerebral side effects are not so severe as to merit immediate sedation and airway protection. Indeed, as shown in table 2, this is a marker of very severe overdose.

Table 2 Symptoms by severity of atropine poisoning (modified from Toxnet) ${ }^{20}$

\begin{tabular}{lll}
\hline Mild symptoms & Moderate symptoms & Severe symptoms \\
\hline $\begin{array}{l}\text { Dry mouth, urinary retention and } \\
\text { constipation }\end{array}$ & $\begin{array}{l}\text { Somnolence, classical mydriasis, flushing, fever and anhidrosis. Mild } \\
\text { agitation, hallucinations and confusion }\end{array}$ & $\begin{array}{l}\text { Agitated delirium, psychosis, hallucinations, seizures, } \\
\text { hyperthermia and coma }\end{array}$ \\
\hline
\end{tabular}


Indeed, in most atropine poisonings there are only mild or moderate symptoms, where supportive management using pro re nata benzodiazepines for agitation or seizures is adequate. ${ }^{4} 820$ There is also evidence that, if a patient can reliably protect their airway and there is recent $(<1 \mathrm{~h})$ ingestion of the atropine, activated charcoal may be of benefit. 420

Physostigmine is a reversible cholinesterase inhibitor; it is a tertiary amine and can therefore cross the blood-brain barrier. This distinguishes it from neostigmine (a more polar quaternary amine), which is used much more commonly to augment reversal of neuromuscular blockade postsurgery or in the treatment of myasthenia gravis. Both drugs work by inhibiting the breakdown of acetylcholine. However, only physostigmine can reverse the significant cerebral effects and can therefore act as an antidote in atropine poisoning, increasing the concentration of acetylcholine to overcome the muscarinic receptor's competitive inhibition with atropine. Therefore, some people recommend its use in moderate-to-severe poisonings. ${ }^{20} 21$ This may lead to lower rates of intubations ${ }^{22}$ and, in one small trial, it was better at controlling delirium and agitation than were benzodiazepines. $^{23}$ Physostigmine is limited, however, in three ways; first, it is a rare drug, meaning it is not always immediately available. ${ }^{4} 20$ Second, it has a short duration of action (45$60 \mathrm{~min}$ ) when compared to atropine (elimination half-life $2 \mathrm{~h}$ ). Third, it is contraindicated if there is co-ingestion of tricyclic antidepressants due to an increase in the rate of arrhythmias and seizures. Therefore, before using physostigmine, it is important to know the aetiology of the poisoning. It may have a role in helping avoid intubation in certain patients or confirming the suspected diagnosis, however, in most situations, supportive care with possible escalation to sedation and intubation is adequate. $^{4} 20$

\section{OUTCOME AND FOLLOW-UP}

Fortunately, the patient made a full recovery from this incident. Before discharge from hospital, our psychological medicine team interviewed her and confirmed that, though the ingestion was deliberate, the very high dose was accidental and of nonsuicidal intent. No long-term follow-up was required.

\section{DISCUSSION}

The use of $A$. belladonna in medicine has a long history. 'Belladonna extract' is described in the very first edition of the British Pharmacopoeia (1864). ${ }^{24}$ This text defined tincture of belladonna, utilising a preparation technique of belladonna leaf and 'proof spirit' $(57 \%$ alcohol) in proportions of approximately $1: 20$.

The modern British Pharmacopoeia (BP) uses belladonna leaf and $70 \%$ alcohol in proportions of $1: 10$ to create Belladonna Tincture $\mathrm{BP}^{25}$ This standard demands that the tincture contain $0.3 \mathrm{mg}$ alkaloid per $\mathrm{ml}$ calculated as hyoscyamine. Atropine is a racemic mixture of the optical isomers $\mathrm{D}$ and L-hyoscyamine, with the L-hyoscyamine isomer being biologically active. The usual dose of Belladonna Tincture BP is $0.5-2 \mathrm{~mL}$, given several times a day, generally as a gastrointestinal antispasmodic.

In this case, the herbalist had access to an A. belladonna preparation supplied by a herbal tincture manufacturer. The manufacturing process employed is very similar to that described for Belladonna Tincture BP. One kilogram of dry belladonna leaf (wild collected) is macerated and cold percolated with $10 \mathrm{~L}$ of an alcohol solution. It is not clear how this use of a weaker alcohol solution (45\%) affects the alkaloid content, if at all. The final liquor is filtered to remove particulate matter, first through a $10 \mu$ filter, then again through a $1 \mu$ filter, before being bottled for sale in $500 \mathrm{~mL}$ bottles.

It is worth noting that the sale of the product is entirely legal. The medicines (retail sale of herbal remedies) order 1977 SI 2130 makes provision for exemptions for herbalists, allowing them to be in possession of and to supply a wide range of products in the course of their practice. Herbal medicines can be sold/supplied by the herbalist following a one-to-one consultation between the herbal practitioner and the client, provided the prescription remains within dose and route of administration limits outlined in Part II of the order. The herbalist can also exceed these limits provided the prescription order generated is fulfilled in a registered pharmacy by or under the supervision of a pharmacist. There is no mandatory training or registration for individuals wishing to practice as a herbal practitioner, although there are several courses available and voluntary registration schemes run by the array of bodies that represent herbalists. Herbalists are able to obtain stock products from several manufacturers and distributors, in the absence of a specific state registration scheme.

In the present case, the bottle had been unopened prior to the incident, so it was possible to calculate the volume consumed-this was found to be approximately $50 \mathrm{~mL}$. Using an estimate of $0.3 \mathrm{mg} / \mathrm{mL}$ alkaloid content, the patient dose was estimated to be in the region of $15 \mathrm{mg}$ of alkaloid. Given that hyoscyamine readily becomes racemic during the extraction process, this would mean that the patient took approximately $15 \mathrm{mg}$ of atropine orally, although there is clearly a significant margin for error. To help contextualise this, the exact fatal dose of atropine is not known, indeed it has a relatively large margin of safety $\left(\mathrm{LD}_{50} 453 \mathrm{mg}\right)^{1}{ }^{13}$ however, $10-20 \mathrm{mg}$ of atropine is incapacitating and, in children, doses of $<10 \mathrm{mg}$ have proved fatal. $^{1}$

To the best of our knowledge, this is the first reported incident of life-threatening atropine poisoning from ingestion of purchased herbal tincture $A$. belladonna preparation in the world literature. The case provides an important warning about the easy and legal availability of potentially lethal preparations and therefore we have not only described the case but have also detailed the manufacture and purchase of the substance.

\section{Learning points}

- The care of atropine poisoning is predominantly excellent supportive care with benzodiazepines to treat agitation, though administration of physostigmine should be considered. Patients may require intubation and ventilation for their agitation.

- The presentation of an acute confusional state is common to the medical take and this case highlights the importance of obtaining a full drug history including use of herbal preparations.

- Finally, and most significantly, our case highlights the availability of potentially lethal substances that are easily obtainable with relatively minimal legal safeguards or specifications relating to the herbal remedy industry.

Acknowledgements The authors would like to acknowledge Hannah Smorzaniuk, pharmacist at the John Radcliffe Hospital, Oxford, who researched much of the data regarding the dosage of Belladona Tincture during the clinical case. 
Contributors AC was the lead author writing the case summary. AA provided the literature search on atropine poisoning and wrote large amounts of the discussion. $\mathrm{MB}$ provided the legal/procedural research on the production of herbalist tinctures and also wrote large amounts of the discussion. JD helped write the concluding statements and provided edits throughout the whole document.

Competing interests None declared.

Patient consent Obtained.

Provenance and peer review Not commissioned; externally peer reviewed.

\section{REFERENCES}

1 Mowry JB, Spyker DA, Cantilena LR Jr, et al. 2013 Annual Report of the American Association of Poison Control Centers' National Poison Data System (NPDS): 31st Annual Report. Clin Toxicol (Phila) 2014;52:1032-283.

2 Family Practice Notebook. http://www.fpnotebook.com/neuro/pharm/ AntchlnrgcTxcty.htm

3 Ramjan KA, Williams AJ, Isbister GK, et al. 'Red as a beet and blind as a bat' Anticholinergic delirium in adolescents: lessons for the paediatrician. $J$ Paediatr Child Health 2007:43:779-80.

4 Glatstein M, Alabdulrazzaq F, Scolnik D. Belladonna alkaloid intoxication: the 10-year experience of a large tertiary care pediatric hospital. Am J Ther 2013: 10.1097/01.mjt.0000433940.91996.16

5 Bogan R, Zimmermann T, Zilker T, et al. Plasma level of atropine after accidental ingestion of Atropa belladonna. ClinToxicol (Phila) 2009;47:602-4.

6 Mateo Montoya A, Mavrakanas N, Schutz JS. Acute anticholinergic syndrome from Atropa belladonna mistaken for blueberries. Eur J Ophthalmol 2009;19:170-2.

7 Cikla U, Turkmen S, Karaca Y, et al. An Atropa belladonna L. poisoning with acute subdural hematoma. Hum Exp Toxicol 2011;30:1998-2001.

8 Heindl S, Binder $C$, Desel $H$, et al. [Etiology of initially unexplained confusion of excitability in deadly nightshade poisoning with suicidal intent. Symptoms, differential diagnosis, toxicology and physostigmine therapy of anticholinergic syndrome]. Dtsch Med Wochenschr 2000;125:1361-5.

9 Oerther S, Behrman AD, Ketcham S. Herbal hallucinations: common abuse situations seen in the emergency department. J Emerg Nurs 2010;36:594-6.

10 Larkin GL. Occupational atropine poisoning via aerosol. Lancet 1991;337:917.
11 Amitai $Y$, Almog $S$, Singer $R$, et al. Atropine poisoning in children during the Persian Gulf crisis. A national survey in Israel. JAMA 1992;268:630-2.

12 Tatsumi M, Groshan K, Blakely RD, et al. Pharmacological profile of antidepressants and related compounds at human monoamine transporters. Eur J Pharmacol 1997;340:249-58.

13 Brunton L, Chabner B, Knollman B. Goodman and Gilman's The pharmacological basis of therapeutics. 12th edn. New York: McGraw-Hill Professional, 2010. ISBN: 978-0-07-162442-8

14 Schep LJ, Slaughter RJ, Beasley DM. The clinical toxicology of metamfetamine. Clin Toxicol (Phila) 2010;48:675-94.

15 Pagliaro L, Ann Marie P. Pagliaros' comprehensive guide to drugs and substances of abuse. Washington DC: American Pharmacists Association, 2004.

16 Dargan PI, Wallace $\mathrm{Cl}$, Jones AL. An evidenced based flowchart to guide the management of acute salicylate (aspirin) overdose. Emerg Med J 2002;19:206-9.

17 Boyer EW, Shannon M. The Serotonin Syndrome. N Engl J Med 2005;352:1112-20.

18 Dosi $\mathrm{R}$, Ambaliya A, Joshi $\mathrm{H}$, et al. Serotonin syndrome versus neuroleptic malignant syndrome: a challenging clinical quandary. BMJ Case Rep 2014;2014:pii: bcr2014204154.

19 Perry PJ, Wilborn CA. Serotonin syndrome vs neuroleptic malignant syndrome: a contrast of causes, diagnoses, and management. Ann Clin Psychiatry 2012:24:155-62

20 US National Library of Medicine. TOXNET. http://www.toxnet.nlm.nih.gov/cgi-bin/sis/ search2/f?./temp/ 8Vr2Cn:3

21 Ceha $L$, Presperin C, Young $E$, et al. Anticholinergic toxicity from nightshade berry poisoning responsive to physostigmine. J Emerg Med 1997;15:65-9.

22 Watkins JW, Schwarz ES, Arroyo-Plasencia AM, et al. The use of physostigmine by toxicologists in anticholinergic toxicity. J Med Toxicol 2015;11:179-84.

23 Burns MJ, Linden $\mathrm{CH}$, Graudins A, et al. A comparison of physostigmine and benzodiazepines for the treatment of anticholinergic poisoning. Ann Emerg Med 2000;35:374-81.

24 General Council of Medical Education and Registration of the United Kingdom. British Pharmacopoeia. London: Stoppiswoode and Co. 1864:343-4.

25 https://www.pharmacopoeia.com/

Copyright 2015 BMJ Publishing Group. All rights reserved. For permission to reuse any of this content visit

http://group.bmj.com/group/rights-licensing/permissions.

BMJ Case Report Fellows may re-use this article for personal use and teaching without any further permission.

Become a Fellow of BMJ Case Reports today and you can:

- Submit as many cases as you like

- Enjoy fast sympathetic peer review and rapid publication of accepted articles

- Access all the published articles

- Re-use any of the published material for personal use and teaching without further permission

For information on Institutional Fellowships contact consortiasales@bmjgroup.com

Visit casereports.bmj.com for more articles like this and to become a Fellow 